\title{
Reanálise de alguns aspectos da vocalização da lateral palatal no português
}

\author{
Evelyne Dogliani Madureira \\ Universidade Federal de Minas Gerais
}

\section{Résumé}

Cet article propose une réfléxion concernant le rôle joué par deux models explicatifs du changement linguistique (le model néogrammairien et celui de la diffusion lexicale) dans le processus de vocalisation de la latérale palatale en portugais. L'analyse prend en compte les caractéristiques du même processus en d'autres langues romanes, le français, surtout. Des facteurs de différentes ordres tels que la derive et le soustrat linguistique, ainsi que les aspects socio-culturels intervenants dans les processus de changement linguistique y sont considérés. 


\section{INTRODUÇÃO}

$\mathrm{E}$ ste artigo propõe uma reflexão sobre a vocalização da lateral palatal no português brasileiro, considerando diferentes estágios desse processo. Um desses estágios é analisado em Madureira (1997), onde a análise desse processo no português contemporâneo de Belo Horizonte evidencia a atuação do modelo da Difusão Lexical, no que concerne à sua implementação de um grupo social para o outro: são apresentadas evidências de que, apesar de o grupo socialmente menos favorecido ser apresentado como aquele ao qual se restringe a pronúncia da variante nãovocalizada da lateral palatal, o grupo socialmente mais favorecido também realiza a variante não-vocalizada da lateral palatal, apresentando, todavia, uma característica distinta do outro grupo; isto é, o fenômeno restringe-se, aí, a alguns itens em determinadas condições de enunciação. A implementação do processo para o grupo socialmente mais favorecido é apontada como tendo seu ponto de origem na conotação afetiva dos itens. Propõe-se a hipótese de futura regularidade do processo condicionada à existência de um contexto fonético favorecedor, fator apontado em Oliveira 1991 e 1992.

Uma reflexão sobre a origem do fenômeno no português brasileiro, orientada pelo fato de que o mesmo não se realiza no português europeu (apesar de se tratar de um processo românico), nos leva a distinguir o fenômeno quanto a sua origem e quanto a sua implementação. Daí resulta o estabelecimento de diferentes estágios: um primeiro estágio evidencia uma mudança regular (fisiologicamente motivada); o segundo e o terceiro, por suas próprias características, trazem indícios de Difusão Lexical. Nesse sentido, pode-se dizer que o quadro de desencadeamento, dentro de um determinado grupo - se admitirmos que todo processo de 
variação tem origem num determinado grupo social e não, na sociedade como um todo, de acordo com Kroch (1978) - terá características bem distintas do quadro de implementação de um grupo para o outro, no qual a difusão do processo atingiria gradativamente o léxico.

Entre as línguas românicas que apresentam vocalização da lateral palatal destacam-se, além do português brasileiro e de excolônias portuguesas, o francês e o espanhol, línguas cujo processo de variação da lateral palatal será descrito nas duas próximas seções. É conveniente iniciar a descrição desse processo pelo de palatalização, processo que antecede e dá base estrutural ao de vocalização.

\section{1 - O PROCESSO DE PALATALIZAÇÃO}

Esse processo é tomado como um fator atuante no de vocalização, já que as características desse último representam uma radicalização do primeiro: levar um som palatal ao fonema palatal por excelência.

\section{francês}

A tendência à palatalização se afirmou a partir do momento em que o latim foi falado por um grupo de populações não-latinas, segundo Dauzat (1950: 39-43), o qual afirma que a mudança de $[l+y]$ a [ $l$ "molhado"] já devia ser efetiva no séc. IV, no que diz respeito ao francês. Nessa língua, o processo de palatalização não se dá de forma linear.

A partir de século IX, a língua francesa passa por um período de suspensão dos processos de palatalização. Esse fato deveu-se às invasões dos germânicos, povo que desconhecia qualquer processo de palatalização. A suspensão do processo atingiu principalmente aqueles grupos que mais se prestavam à palatalização, a saber $\left[l^{y}\right]$ e $\left[n^{y}\right]$, conforme atesta Dauzat (1950: 57, 65). Do século XIV ao XVI, o som palatal se confunde com o alveolar, através da escrita uniforme: a grafia $i l$ passou a representar tanto $i+$ lateral alveolar 
quanto $i+$ lateral palatal, o que contribuiu para confundir duas séries originariamente distintas. Quando se tratou de repronunciar a consoante final, já não se sabia se a mesma era alveolar ou palatal. Resulta, desse processo, que algumas palavras apresentam, ainda no século XX, duas ou três pronúncias, ou seja, duas ou três variantes, cuja forma padrão se apresenta, por vezes, em desacordo com a etimologia. Dauzat reporta que o falante hesita, às vezes, entre gri, griye gril, na pronúncia de gril (grelha) e entre bari, baril para baril (barril) ou ainda entre fourni fournil para o vocábulo fournil (forno).

É interessante observar que na análise desse processo de variação, Dauzat aponta a interferência de fatores (que, mais tarde, serão sistematizados pela sociolingüística), tais como a escolaridade. Interessa-nos mais especificamente sublinhar que ao fazer uso de um parâmetro cultural, Dauzat acaba apontando um outro fator atuante: o item lexical. O autor demonstra que a reconstrução da pronúncia foi variável de acordo com o contexto de uso dos itens: palavras pouco usadas, aprendidas na escola, como fenouil (erva-doce), conservaram a lateral palatal, contrariamente a palavras muito freqüentes como genou (joelho), pou (piolbo), e verrou (ferrolbo) que a perderam. O mesmo se dá com palavras técnicas que são tradicionais para os especialistas, apenas: um padeiro diz fourni, um vinhateiro dirá bari, enquanto aqueles que aprenderam essas formas através da leitura dirão fournil, baril, pronunciando com lateral alveolar a consoante final. ${ }^{1}$

A estabilidade política do período de 1610 a 1789 vai trazer novas mudanças lingüísticas, entre as quais o reaparecimento das palatalizações interrompidas por oito séculos. Algumas foram contidas e anuladas pelo esforço dos gramáticos, como as palatalizações de $t$ e $d$. Paralelamente, se dá a vocalização da lateral palatal. 


\section{O português}

O processo de palatalização parece ser mais tardio, no português, no qual as origens da lateral palatal são basicamente equivalentes às do francês, ou seja, o fonema resulta dos seguintes grupos latinos: $-c l,-f l,-p l,-b l,-g l$ (quando precedidos de vogal) e $l y$.

As geminadas - $l l$ do latim que resultaram na lateral palatal em certas línguas, simplificaram-se tanto no português quanto no francês (Coutinho, 1969:121). Segundo Williams (1975:85), os casos de -ll intervocálico do latim clássico que resultaram em -lh, no português, são empréstimos do espanhol: beryllum > brilho, bem como o são, conforme Câmara Jr. (1979:53) os raros casos de palatal inicial, no português.

O fato é que a presença de uma lateral alveolar palatalizada ou de uma lateral palatal registra-se na ortografia portuguesa desde o século XI. Williams (1975:36) diz:

"Pedro A. d'Azevedo assevera (RL.IX.163) que a primeira ocorrência datada de lh é num documento de 1269. (...) Entretanto estas datas podem ser ligeiramente recuadas, pois o LIVRO DE D. JOÃO PORTEL que Pedro A. d'Azevedo publicou subseqüentemente consigna lh em lha num documento de $1267 . "$

É evidente que, se a palatalização aparece na escrita do séc. XI, sua incorporação à língua oral já devia apresentar um tempo razoável de fixação. Vasconcellos (1901: 9-12) aponta a grafia ovelia em documentos do séc. X, o que prova, segundo o autor, que a essa época já se dizia ovelha: o escriba, sabendo que a forma latina -lia era representada por lhem português (ex. filha, filia), e pretendendo reconstituí-la, produziu por erro a forma ovelia (cf. latim ovic'la).

Ainda assim, dois outros fatores sugerem que esse processo, bem como outros, se deu tardiamente no português: a romanização da Ibéria precede a de outras regiões apesar de ser posterior à da Itália. Associado esse fato ao de que a Lusitânia não participou da vida lingüística de Roma (Câmara Jr., 1979: 23), como o fizeram outras regiões (da Ibéria, inclusive), faz sentido pensar que aí seriam 
mais preservadas as formas vigentes em Roma, no início de seu processo de expansão. Inúmeros casos de línguas transplan-tadas evidenciam esse fenômeno: características quinhentistas no português brasileiro atual são exemplo disso. É possível, então, que a lateral seguida de iode se realizasse mais como alveolar palatalizada do que como palatal propriamente. Foi longa, no português, a permanência do valor silábico do $e$, em hiato, o que atesta, segundo Williams (1975: 89), a formação relativamente tardia do iode no território português. A introdução de um iode junto à lateral alveolar resulta numa palatalizada que, no português, por ausência de uma lateral palatal propriamente dita, permaneceu por mais tempo no seu ponto de articulação de origem, e, conseqüentemente, com menos tendência a vocalizar-se na semivogal palatal.

\section{2 - A VOCALIZAÇÃO NAS LÍNGUAS ROMÂNICAS O francês}

No francês, o processo aparece no séc. XVII. Segundo Dauzat (1950:95), os primeiros exemplos atestados estão nos Mazarinades: cayou ao invés de caillou (pedregulbo). Um pouco mais tarde, Hindret reprova à burguesia parisiense essa pronúncia, como em bouteye (garrafa), bouyon (caldo).

A propagação desse fenômeno por quase todo o território francês (algumas regiões do sul da França ainda conservam a lateral palatal) é invariavelmente associada à Revolução Francesa. Wartburg (1962: 229) explica que, assim como na mudança de we para wa não há inovação, mas, uma aceleração de um processo antigo na língua, devido à revolução, também na vocalização há a aceleração de um processo identificável na fala do povo parisiense desde o séc. XVII.

Ligado a esse processo, o francês atual registra palavras tais como, ville (cidade), mille (mil) e tranquille (tranqüilo) que se pronunciam com a lateral alveolar. Outras, com a mesma grafia, em - ille, apresentam paralelamente à realização com a lateral alveolar, uma realização com a semivogal palatal. Essa variação tem sido, aliás, 
registrada em dicionário, para alguns itens lexicais e destaca um aspecto importante: é possível que, no caso de alguns itens, a variação se prenda ainda ao antigo processo de reconstituição da lateral palatal, no qual algumas recuperaram a lateral palatal que depois se vocalizou, outras se reestruturaram com a lateral alveolar e permaneceram como tais e ainda outras perderam suas consoantes finais, como vimos. Interessam-nos, aqui, os dois primeiros fatos. A ortografia não distingue esses dois primeiros grupos. Portanto, atualmente, a partir de formas ortograficamente representadas por - ille, que representaram a variação no séc. XVII, observa-se a variação $[l] \sim \mathcal{}]$. Martinon (1912: 265-266) afirma:

"les finales muettes en -ille-Ces finales sont presque toutes mouillés, comme les finales en -aille, eille, -euille et ouille, étant donné que les finales non mouillées sont presque toutes en -ile avec un seul 1. Portant il y a des exceptions, quoiqu'elles tendent à disparître, par l' effet de l'analogie.(...) Autrefois il y en avait bien davantage, par exemple, genti(l)le avec genti(l)lesse (...) et pasti(l)le qu'on ne connaît plus du tout. Nous assistons actuellement à la transformation de osci(l)le et vaci(l)le en osciye et vaciye."

Essa variação em curso, no francês, evidencia, em primeiro lugar, a interferência da norma culta sobre processos de mudança ou variação lingüística, da seguinte maneira: parece-me que se o sistema ortográfico francês tivesse assimilado a mudança da lateral palatal para a semivogal palatal, a atual variação entre [ $l]$ e $[y]$ talvez não estivesse ocorrendo. A ortografia francesa condensa neste momento duas funções antagônicas da norma culta, que se assenta na simetria e na conservação: ao manter -ille até o séc. XX nos itens que, desde o séc. XVIII, se pronunciam com [y], a ortografia:

a) prolonga, por um lado, a recusa que a norma culta expressava (em nome da conservação) diante da mudança no séc. XVIII;

b) provoca, por outro lado, (em nome da simetria) uma variação no séc. XX, em que [ $l]$ muda para $[y]$. Se, por paralelismo, 
essa mudança se estender para outros grupos que não aqueles em -ille, a norma culta expressará novamente recusa diante da nova variação. ${ }^{3}$

\section{O espanhol}

A língua que mais se aproxima do francês com relação à vocalização da lateral palatal é o espanhol, em que o fenômeno recebe o nome de yeísmo. O processo iguala as duas línguas no que diz respeito à época de origem e à propagação.

Ambas as línguas registram a variação em épocas aproximadas: o francês, no séc. XVII; o espanhol, na segunda metade do séc. XVIII (Allonso, 1967:174).

O fenômeno se observa tanto em regiões contíguas quanto distanciadas, mantendo-se a variação no nível regional, em ambas as línguas. No francês, a lateral palatal sobrevive na Suíça e em parte do sul da França. No espanhol, tanto a Espanha quanto a América registram variação. A Andaluzia apresenta zonas lheístas e outras yeístas assim como Murcia, Extremadura, Castilla la Nueva, ao passo que a Argentina é yeísta, salvo em regiões próximas ao Paraguai, onde a conservação da lateral palatal parece ser geral. O Chile dividese em regiões yeístas mais a sudoeste e regiões lheístas ao norte, ao centro meridional e ao sul. (Allonso, 1967:176-197).

Por outro lado, o yeísmo distingue o espanhol do francês, nos seguintes aspectos: instauração como padrão, características fonéticas das variantes, ciclo de transformação da palatal.

A padronização da semivogal palatal parece mais rápida no francês do que do espanhol em que $[y]$ ainda parece estar em processo de padronização. Allonso (1967:160) considera que a situação das variantes no espanhol do séc. XX são comparáveis às do francês do séc. XIX, sem, todavia, apresentar arraigamento profundo que justifique o ensino da variante mais nova pela escola.

Quanto às características fonéticas das variantes, podemos observar que no francês dos dois séculos passados, a alternância se 
ateve à variação da lateral palatal e da semivogal palatal. Vimos, acima, que há outra variação em curso, no francês atual - [l] [y]indiretamente ligada àquela da qual tratamos agora. No espanhol, ela se vê acrescida, sempre no nível regional, da variantes [ $z$ palatal], $[y]$ e [y surda], sendo [ $z$ palatal] mais generalizada na América do que na Espanha. Acrescenta-se, ainda, a síncope de $[y]$ : gallina $>$ gayina > gaina (Allonso, 1967:181-193).

Quanto ao ciclo de transformação da lateral palatal, não há indícios de vocalização da mesma, no francês, antes do séc. XVII. A língua espanhola, ao contrário, registra dois processos distintos, em termos de época e características fonéticas, segundo Bourciez (1946:411):

"Au Nord, $l$ [molhado] s'est réduit a $y$ (astur. fueya); au Centre, il est passé directement, vers le début du XII ${ }^{\mathrm{e}}$ siècle à $z$ [palatal] devenu $x$ au XVI ${ }^{\mathrm{e}}$, esp.hoja, hijo. (...) Lorsqu'au XIII ${ }^{\mathrm{e}}$ siècle, $l l$ intervocalique s'est mouillé au Centre (mais non en Portugal ce $l$ secondaire n'est plus passé à $z$ [palatal] mais est resté intact dans esp. silla, caballo. (...)"

Allonso (1967:163) rotula ambos os processos de yeísmo e especifica:

“(...) Ese yeísmo leonés (...) se cumplió solamente en la posición intervocálica de una elle muy antigua que se corresponde con la castellana (muyer, pero lluna). Otro es el yeísmo que aqui nos ocupa como materia principal, cronologicamente inagrupable con el anterior, el de una $l$ tardía (con relación a la de muller) procedente de $p l$ - $c l$ - $f l$ latinas (llamar,. lluvia). Esta $l l$ se pronunció en España hasta el siglo XVIII."

Portanto, do primeiro processo de mudança da lateral palatal (séc. XII) temos hoje, no espanhol, a realização [x], do segundo (séc. XVIII), temos a variação da lateral palatal com a semivogal palatal. 


\section{O português}

O português falado em Portugal é, curiosamente, a única língua latina que não registra, em momento algum de sua história, uma transformação da lateral palatal para a semivogal palatal. Os únicos registros de vocalização ocorrem, de acordo com Leite de Vasconcelos (1901:158-200), no português falado no Brasil; em outras colônias portuguesas; nos dialetos crioulos: do Ceilão, de Singapura, do arquipélago do Cabo Verde e da Ilha de São Tomé e num codialeto do português, o guadramilês. Por corresponder esse codialeto a uma região fronteiriça à Espanha, o fenômeno tende a ser interpretado como influência espanhola.

A vocalização da lateral palatal, no Brasil, tem sido comumente associada à fala de índios e negros. O fenômeno consta das alterações fonéticas de origem africana relacionadas por Mendonça (1973:61-62), cuja análise encontra respaldo em Melo (1975:81) e em Silva Neto (1970:595), que afirma:

"não importa que fenômeno igual ou semelhante se tivesse dado no transcurso da evolução da língua francesa ou de qualquer outra... No nosso caso particular e histórico, observamos que os aloglotas (mouros, índios e negros) se mostraram sempre incapazes de pronunciar $l h . "$

O fato é que, se, num determinado momento a vocalização da lateral palatal foi típica do falar de índios e negros, ela é, hoje, característica do falar caipira conforme Amaral (1976: 48) e Rodrigues (1974:162), e, nos centros urbanos, característica das classes baixas e não-escolarizadas.

Paralelamente, registra-se a variante lateral alveolar [ $\not]$ como em mulé(mulher), que é, de modo geral, considerada como característica da fala do nordeste brasileiro, embora ocorra em outras regiões: em Belo Horizonte, segundo Oliveira (1983) e em Piracicaba, de acordo com Rodrigues (1974).

Oliveira (1983) apresenta análise quantitativa e qualitativa da variável (lh), em Belo Horizonte, chegando às seguintes conclusões: 
a variante $[y]$, que não apresenta a evidência de tempo aparente, é estigmatizada, tem seus percentuais de realização nos grupos socioeconômicos mais baixos e ocorre, ainda que de forma esporádica, nos grupos mais altos. Além disso, é favorecida pelo estilo informal e desfavorecida pelas mulheres, o que evidencia seu status de estereótipo. A variante [ $l]$ apresenta-se com as características de uma variante em extinção na medida em que se realiza, preferencialmente, na fala dos mais velhos. Nos grupos mais baixos, é favorecida pelo estilo formal, o que lhe empresta o caráter de variante de prestígio em relação à variante $[y]$.

Madureira (1987) apresenta indícios de que a variante [y] se implementa, em Belo Horizonte, de um grupo socioeconômico mais baixo (G2) para o outro, mais alto (G1), por Difusão Lexical. Dentre os parâmetros estruturais considerados, o único a apresentar algum grau de favorecimento foi o fator item lexical. Isto é, a análise revelou que o G1 apresentou vocalização em dois itens lexicais: trabalhar e velho. No G2, esses dois itens receberam os maiores percentuais de vocalização. Foi identificado, além disso, que o favorecimento desses dois itens relacionava-se a contexto de fala afetivo.

Madureira (1997) reavalia o parâmetro conotação dos itens lexicais enquanto fator de mudança e apresenta reflexão sobre a compatibilização dos conceitos de mudança, variação e alteração de sentido.

A próxima seção propõe uma reflexão sobre o papel do contexto lingüístico no processo em análise.

\section{3 - A ATUAÇÃO DO CONTEXTO LINGÜÍSTICO NA VOCALIZAÇÃO DA LATERAL PALATAL}

Oliveira (1991 e 1992) procura demonstrar que todas as mudanças se dão por Difusão Lexical, através de itens lexicais cujas características fonético-fonológicas determinam um maior ou menor grau de expansão da nova forma. Pressupõe sua explicação que aqueles processos que propiciam uma configuração absolutamente 
regular são aqueles cuja mudança se dá em um contexto fonético favorecedor, o qual atua posteriormente ao surgimento da mudança.

São divergentes as opiniões quanto à atuação do contexto lingüístico no processo de variação que ora nos ocupa. Primeiramente, porque uma das variantes, apenas, revela atuação do contexto fonético: a realização [ $l$ em lugar da consoante lateral palatal tem um contexto fonético favorecedor - a vogal seguinte $/ e /$ ou $/ i /$. Nos demais contextos, a variação não é sensível a contexto fonético, caracterizando-se como mudança fisiologicamente motivada.

Poder-se-ia, então, lançar mão do fator simplificação articulatória, para explicar o fenômeno da vocalização. Trata-se, entretanto, de um fator cuja consideração é polêmica. Choca-se o mesmo à produtividade de outros fenômenos de mudança cuja característica é oposta. O próprio processo de palatalização, que antecede, como vimos, o da vocalização, caracteriza-se de forma diametralmente oposta: se neste há a simplificação de um fonema, naquele observase a criação de um novo ponto de articulação - o dorso da língua em direção ao palato, que cria, além disso, um fonema mais frágil relativamente a outros, considerado o sistema no qual se insere. Nem por isso, o processo de palatalização deixou de ser produtivo do latim para as línguas românicas. Ainda assim, não faltou quem dissesse que o celta levara a língua pela via da preguiça (Henri Hubert, les Celtes, I, 63, apud Dauzat (1950, p. 11). Ora, as palatalizações, como vimos, se dão nas línguas de substrato celta.

Atentando para esse aspecto da questão, Kroch (1978) sugere que se substitua o fator facilitação articulatória, por outro, o da naturalidade da mudança. De acordo com Kroch, uma mudança caracteriza-se como natural quando é comum a um determinado grupo de línguas. Esse fator nos é conveniente: os processos de palatalização e de vocalização têm um ponto em comum: ambos são românicos. Podemos assim relacioná-los enquanto mudanças naturais apesar de suas características divergentes. ${ }^{4}$

Ainda assim; se, por um lado, a ocorrência de vocalização na maior parte das principais línguas românicas sugere que se trata de 
uma mudança fisiologicamente motivada, por outro, a sua ausência no português lusitano se nos apresenta como contra-exemplo para tal. Sabemos não ser possível alegar aqui qualquer influência de substrato lingüístico, já que o celta é elemento comum à Península Ibérica e à Gália. Poder-se-ia argumentar que o fenômeno não se realizou ainda nessa língua por ser diferente o quadro de transplantação do latim para a Lusitânia, nos aspectos que apontamos acima, o que teria provocado retardamento de palatalização e conseqüente retardamento da vocalização. Se considerarmos, todavia, o período de emergência do fenômeno no francês e no espanhol, diremos que já houve tempo suficiente para que o mesmo se manifestasse no português de Portugal. Mesmo sob essa ótica de deriva lingüística, podemos ainda argumentar o seguinte: já que há consenso nas pesquisas lingüísticas atuais quanto ao fato de que as condições sociais interferem na agilização ou no retardamento, bem como na inibição de processos lingüísticos, é possível pensar que, chegado o momento de manifestação tardia do processo no português, o mesmo não encontrou terreno fértil, dadas as novas condições sociais da população, quais sejam, a aquisição da escrita, importante fator de desencadeamento ou inibição de mudança lingüística. À luz dessa hipótese, pode-se até prever que o fenômeno não seja desencadeado nessa população.

Se, por outro lado, observarmos a sistemática ocorrência do fenômeno de vocalização no português transplantado, somos obrigados a considerar a atuação do substrato lingüístico. No caso do português brasileiro, não me parece ser coincidência o fato de serem os escravos apontados como os difusores da vocalização da lateral palatal e o fato de suas línguas originárias não conterem a lateral palatal. Duas observações me levam a essa reflexão:

a) a constatação de que um bom número de falantes do grupo socialmente menos favorecido desconhece a articulação da lateral palatal, ou seja, toda e qualquer palavra contendo a variável é sistematicamente pronunciada com a semivogal palatal, inclusive aquelas que integram as listas de pares 
mínimos do tipo teia - telha, vazia - vasilha. A única exceção aparece quando a variável é seguida de / $i /$ ou / el realizando-se, então, como lateral alveolar;

b) a aquisição tardia da lateral palatal pela criança que, até começar a pronunciá-la (e isto se dá por itens lexicais), a substitui pela semivogal palatal, para todo e qualquer item lexical, ou pela lateral alveolar se o segmento seguinte imediato for $/ e / \mathrm{ou} / i$.

Entendo, portanto, que, igualmente ao processo de aquisição da fala pela criança, na aquisição do português pelas populações indígenas e africanas houve uma mudança foneticamente e lexicalmente abrupta. O fonema lateral palatal passou a $[y]$ imediatamente e para todos os itens. O que acontece é que essa mudança só tem status de mudança do ponto de vista do sistema lingüístico. Do ponto de vista dos falantes, não houve mudança. Por se dar o fenômeno num processo de aquisição de segunda língua, podemos dizer que as entradas lexicais contendo a lateral palatal foram adquiridas com a semivogal palatal.

O processo de variação se deu num segundo momento, e aí, sim, do ponto de vista do falante: sob atuação da norma culta (nesse caso, o falar dos portugueses colonizadores), a lateral palatal vai sendo reincorporada, isto é, corrigida no falar da população negra, caracterizando um fenômeno de variação. Observando a fala atual do grupo social menos favorecido, podemos inferir algumas características desse processo de variação.

Tenho fortes razões para acreditar que, nesse segundo momento do processo, a tentativa de correção da lateral palatal se tenha dado por difusão lexical, num processo que decorreria do seguinte fator: os movimentos sociais que levaram o elemento negro a contatos com o elemento português, em situações formais, deram início a um processo de correção que:

a) submetendo-se aos princípios de atuação dos estilos de fala, conforme estabelecidos pela Teoria da Variação; 
b) variável de acordo com a posição que o indivíduo corrigido ocupava na rede de relações sociais (Milroy, 1980); ${ }^{5}$ do que decorre c;

c) implementando-se de um falante para o outro (Shen 1990); ${ }^{6}$

deverá ter atingido determinados itens lexicais, isto é, aqueles que iam surgindo nesses contatos.

Acrescente-se a essa movimentação social a miscigenação das raças, o que expôs a geração descendente a uma variação em seu próprio meio familiar: o pai pronunciando com consoante lateral palatal palavras como mulher, e a mãe pronunciando-as com [y], por exemplo. O fato é que, a partir de um determinado momento, o processo de variação, que, no primeiro estágio, caracteriza grupos com substratos lingüísticos distintos, passa a ser também característica intragrupal, através dos movimentos sociais da nova comunidade que se formava.

Não disponho de evidências que ilustrem esse segundo estágio, mas a observação do processo de reintrodução da lateral palatal no francês descrita por Dauzat e apresentada acima neste texto pode corroborar essas reflexões: como vimos, de acordo com Dauzat, a reintrodução da lateral palatal no francês atingiu certos itens em detrimento de outros, (ou seja, os itens atingidos foram basicamente aqueles veiculados no âmbito escolar, já que se tratava de um processo de correção de um fonema). Considerando que o segundo estágio do processo de variação da lateral palatal, no português, se caracterizaria também como correção sobre um fonema, processo consciente do ponto de vista do falante, parece-me lícito pressupor que o mesmo se tenha dado por Difusão Lexical, conforme aconteceu no francês.

Observações não-sistemáticas no português atual também corroboram a formulação dessa hipótese com indícios do seguinte tipo: um falante (de nível universitário) admite que, como todo mundo na sua casa fala $[y]$, ele também fala $[y]$, dentro de casa. Fora, ele se esforça por pronunciar a consoante lateral palatal, e é geralmente bem sucedido, exceto em algumas palavras, que saem 
sempre com [y]. Ex.: orelha. Um outro "confessa" saber que debulhar pronuncia-se com a lateral palatal, mas ele só pode pronunciá-lo com [y], se quiser, de fato, expressar a atividade da qual participava, na infância: debulhar o milho. Paralelamente, minha observação desse falante (também de nível universitário) mostrou que outros itens lexicais contendo a variável eram naturalmente pronunciados com a lateral palatal.

Um terceiro elemento vem ao encontro da análise que proponho para esse segundo estágio da variação da lateral palatal. Por ser um processo de correção (da semivogal palatal para a consoante lateral palatal), trata-se, de acordo com Labov (1994:78), de uma mudança from above, isto é, acima do nível da consciência. Esse tipo de mudança é relacionado pelo autor entre aquelas passíveis de se darem por Difusão Lexical:

"lexical diffusion is the result of the abrupt substitution of one phoneme for another in words that contain that phoneme. The older and newer forms of the word will usually differ by several phonetic features. This process is most characteristic of the late stages of an internal change that have been differentiated by lexical and grammatical conditioning, or has developed a high degree of social awarness or of borrowings from other systems ('change from above')." (p.542)

Portanto, o quadro de variação na vocalização do grupo social menos favorecido, conforme descrito tanto em Oliveira (1981), quanto em Madureira (1987), seria resultante desse segundo estágio da variação da lateral palatal, em que temos: falantes que não articulam a lateral palatal, falantes que apresentam variação aleatória (ora o item aparece com vocalização, ora com a lateral palatal, sem que se possa atribuir interferência de estilo ou contexto de fala). Seria esse o quadro resultante de um processo de correção que:

a) não atingiu ainda um determinado grupo de falantes;

b) atingiu um grupo de falantes através de alguns itens lexicais;

c) atingiu um grupo de falantes para todos os itens em situação de estilo de fala formal. 
A variação no grupo social mais favorecido, descrita em Madureira (1987 e 1997) caracteriza um terceiro estágio do processo de variação. O fato de o processo apresentar favorecimento de alguns itens em função de especificidade de sentido e conotação afetiva dos mesmos, situa também esse terceiro estágio entre os processos que se caracterizam como mudança from above. Novamente se relacionam, portanto, processos que se dão acima do nível de consciência do falante e que são implementados por Difusão Lexical. $^{7}$

Apesar de intuitivo em alguns pontos (especificamente na delineação do segundo estágio), o perfil de variação da lateral palatal no português brasileiro, conforme sugerido nesse texto, me parece bastante viável, tanto quando confrontado a dados reais atuais, como quando comparado a fenômenos similares em outras línguas. Shen (1990) nos diz: "We believe that by extrapolating from some synchronic observations, many important aspects of a total linguistic change can be learned".

A possibilidade de determinar diferentes direções num processo de variação tido até então como linear pode nos ajudar a refletir sobre o quanto tanto a perspectiva neogramática quanto a difusionista se submetem a fatores sociais, tendo sua produtividade determinada pelo dinamismo dos mesmos.

\section{CONCLUSÕES}

Esse $\operatorname{artigo~}^{8}$ pretendeu apresentar mais algumas reflexões sobre a atuação do modelo da Difusão Lexical, no processo de vocalização da lateral palatal. Analisada a vocalização sob a ótica de fenômeno românico, foi possível refletir sobre a atuação de fatores tais como o substrato lingüístico, o que no caso do português brasileiro, permite propor-se a hipótese de que o percurso da variável não é linear, submetendo-se a mesma ora à atuação de fatores tais como o substrato lingüístico (onde se delineia uma mudança fonológica regular), ora à atuação da norma culta (processo cujas características 
implicam difusão por itens lexicais). A atuação desse último fator teve por base as conclusões apresentadas por Labov (1994) sobre o mesmo, bem como o histórico do processo no francês e os indícios de variação no português atual de Belo Horizonte. ${ }^{?}$

\section{NOTAS}

${ }^{1}$ O PETIT ROBERT, da ed. de 1977, aponta variação para baril, mas não, para fournil, item para o qual registra apenas a pronúncia sem a lateral alveolar final. Sendo o texto de Dauzat de 1950, é possível que a variação que ele aponta estivesse já em extinção, ou se circunscrevesse a um grupo social ou região específicos.

${ }^{2}$ Cumpre observar que o Petit Robert da edição de 1977 não registra a variação para o primeiro representando-o por [osil], exclusivamente; para vacille, estão registradas as duas pronúncias.

${ }^{3}$ Naturalmente, essa recusa depende do ponto de surgimento da mudança. Por se tratar de um processo from above (cf. abaixo, no texto), ela surgiria no grupo dominante, sendo, nesse caso, sustentada pela norma culta.

${ }^{4}$ Numa crítica a uma parte do trabalho de Labov, Kroch explicita que, apesar de suas pesquisas apresentarem considerável evidência de que os grupos sociais mais baixos são mais suceptíveis que o grupo dominante aos processos de mudança foneticamente motivados, Labov não explicita tal comportamento como princípio nem tampouco propõe uma explicação para o mesmo. Na crítica de Kroch, Labov limita-se a tentar demonstrar que a explicação que associa mudanças lingüísticas a facilitação articulatória é ilegítima já que a análise de mudanças vocálicas em progresso no vernáculo das classes trabalhadoras evidencia um aumento do esforço muscular despendido para a articulação das variantes padrão e, assim agindo, insere-se na mesma lógica daqueles que associam preguiça e facilitação articulatória. Deve ser outro, diz Kroch, o foco da análise. Subjacente à argumentação de Labov e de outros lingüistas, permanece a postura (extraída da análises anteriores à sociolingüística) de se considerar a mudança lingüística do ponto de vista de sua implementação (e não de sua origem) e a conseqüente convicção de que as mudanças se implementam na medida do prestígio do grupo que as adota. $O$ autor nos faz, então, observar que essa linha de raciocínio nos levaria, por exemplo, a considerar, na análise de certas mudanças lingüísticas, o grupo dominante como mais sensível às mudanças foneticamente motivadas. A 
solução encontrada por Labov para conciliar a hipótese que relaciona prestígio e implementação com as evidências apresentadas pelas pesquisas sociolingüísticas é a de postular noções de prestígio internas a cada grupo, de acordo com proposta de Ferguson e Gumperz (1960). A essa postulação Kroch chama "pluralismo lingüístico" e considera que, apesar de mais coerente com a realidade lingúistica evidenciada pelos trabalhos sociolingüísticos (já que deixa pressupor que a mudança pode surgir em qualquer grupo social), a nocão de pluralismo lingüístico revela-se inócua no que diz respeito a uma proposta de explicação para a implementação de mudanças foneticamente condicionadas pelos grupos sociais mais baixos, conforme suas próprias pesquisas evidenciam.

${ }^{5}$ De acordo com Milroy (1980), o fato de cada comunidade exibir um padrão de redes sociais que lhe é típico, deve ser levado em conta, na análise dos fenômenos lingüísticos. A localização do falante na rede social permite compreender melhor e até prever o curso de uma mudança na comunidade em questão.

${ }^{6}$ Comparando a implementação de um fenômeno lingüístico ao espraiamento de uma epidemia, Shen procura demonstrar, através da análise da fusão de / ã/ e / $\tilde{a} /$ no dialeto de Shangai, que os fatores item lexical, falante e tempo se interrelacionam na mudança lingüística de tal forma que o perfil da mudança é um, no desencadeamento do processo, e outro bem diverso, na etapa final: se, no início, a adoção da nova pronúncia descreve um longo intervalo de tempo de um falante para o outro, e, conseqüentemente, de uma palavra para a outra, na etapa final, ao contrário, à medida que aumenta o número de falantes atingidos, diminui o intervalo de tempo gasto para que um novo item seja alcançado. Apesar de intuitiva, por basear-se num modelo matemático não verificado ainda com dados reais, a proposta de Shen é interessante, pelo que acrescenta o fator falante (indivíduo) à análise do modelo da Difusão Lexical. Implica, como tal que as idiossincrasias da organização social terão papel determinante na expansão da mudança.

${ }^{7}$ Apesar de o fator interveniente no processo ser de ordem semântica, o que altera as condições de verdade, cuja identidade deve caracterizar as variantes lingüísticas, de acordo com a Teoria da Variação, a variável contida nos itens que embasam as reflexões deste texto é descrita em termos de variantes lingüísticas, já que nos dois grupos sociais pesquisados, os itens recebem as duas pronúncias, tanto no contexto de fala afetivo quanto no referencial.

${ }^{8}$ Os dados relativos ao francês e ao espanhol, apresentados neste texto foram, em parte, embasados em Madureira (1987).

9 Agradeço aos dois pareceristas anônimos a leitura e avaliação deste artigo. Esclareço ao parecerista que discorda de minha avaliação relativa ao fator da simplificação articulatória que, apesar de não ser minha a argumentação, endosso a análise de Kroch. Se esse fator "tende a atuar com mais intensidade em situações de contato de línguas", ele poderia ter atuado no processo de vocalização; pela 
mesmas razões, entretanto, esse fator deveria ter inviabilizado aquele que o precedeu, o de palatalização. Nesse sentido, a consideração do fator naturalidade da mudança me parece mais produtivo pela generalidade que permite. Ao mesmo parecerista, esclareço, ainda, que mantenho a afirmação de que, do ponto de vista das populações indígenas e africanas, não houve mudança, porque entendo que seus falantes não alteraram seu sistema fonológico: desconheciam a articulação da lateral palatal em suas línguas de origem e, na aquisição do português, continuaram a ignorá-la, substituindo-a pela semivogal palatal, fonema que lhes era familiar e preserva um dos traços da consoante. Tal forma de aquisição desencadeou a variação a que me refiro na seqüência do texto. Esse processo, sim, nos obriga a considerar variação no sistema. Fico muito grata se, na hipótese de continuar havendo discordância e/ou incompreensão quanto à análise que proponho, me for dada a oportunidade de refletir sobre qualquer fator adicional.

\section{REFERÊNCIAS BIBLIOGRÁFICAS}

ALONSO, A. Estudios linguisticos: temas hispanoamericanos. Madrid: Editorial Gredos, 1967.

AMARAL, A. O dialeto caipira. São Paulo: Hucitec, 1976.

BOURCIEZ, E. Éléments de linguistique romane. Paris: Librairie C. Klincksiek, 1946.

CÂMARA JR, J.M. História e estrutura da lingua portuguesa. Rio de Janeiro: Padrão, 1979.

COUTINHO, I. L. Gramática histórica. Rio de Janeiro: Livraria Acadêmica, 1969.

DAUZAT, A. Phonétique et grammaire bistoriques de la langue française. Paris: Librairie Larousse, 1950.

KROCH, A. Towards a theory of social dialect variation. Language in Society, 7 , p.17-36.

LABOV, W. Principles of linguistic change : internal factors. Oxford \& Cambridge: Blackwell, 1994.

MADUREIRA, E. D. Sobre as condições de vocalização da lateral palatal no português. Belo Horizonte: Faculdade de Letras da UFMG. (Dissertação, Mestrado ), 1987.

. Difusão lexical e variação fonológica: o fator semântico. Revista de Estudos da Linguagem. Belo Horizonte: Faculdade de Letras da UFMG, p.5-22, Jan./ Jun., 1997. 
MARTINON, P. Comment on prononce le français. Paris: Librairie Larousse, 1913. MELO, G. C. A língua do Brasil. Rio de Janeiro: FGV, 1975.

MENDONÇA, R. A influência africana no português do Brasil. Rio de Janeiro: Civilização Brasileira, 1973.

OLIVEIRA, M. A. de. Variation and change in brazilian portuguese: the case of the liquids. Universidade da Pensilvânia. (Tese, Doutoramento), 1983.

. The neogrammarian controversy revisited. International Journal of the Sociology of Language. Berlin, vol.89, p.93-105, 1991.

Aspectos da difusão lexical. Revista de Estudos da Linguagem Belo Horizonte: Faculdade de Letras da UFMG, p. 31-41, Jul/Dez.,1992.

RODRIGUES, A. N. O dialeto caipira na região de Piracicaba. São Paulo: Ática, 1974.

SHEN, Z. Lexical diffusion: a population perspective and a mathematical model. Journal of chinese linguistics, vol.18, p.159-201, 1990.

SILVA NETO, S. História da língua portuguesa. Rio de Janeiro: Livros de Portugal, 1970.

VASCONCELLOS, J. L. Esquisse d'une dialectologie portugaise. Paris: Aillaud, 1901.

WARTBURG, W. v. Évolution et structure de la langue française. Berne: Éditions A. Francke, 1962.

WILliAMS, E. B. Do latim ao português: fonologia e morfologia históricas da língua portuguesa. Rio de Janeiro: Tempo Brasileiro, 1975. 